\title{
QUEVEDO EN REVISIÓN CON SUS CONTEMPORÁNEOS: EL CASO DE CERVANTES ${ }^{1}$
}

\author{
Isabel Pérez Cuenca \\ Universidad San Pablo-CEU
}

La bibliografía que pone en contacto la obra de Cervantes con la de Quevedo es escasa si la comparamos con el ingente número de estudios publicados sobre ambos autores en los que se analizan diversos aspectos de sus vidas y obras. ${ }^{2}$ Sin lugar a dudas, las vidas de estos autores son harto diferentes y los puntos coincidentes entre ellas apenas existen.

Francisco de Quevedo nace en el año 1580, 33 años después que Miguel de Cervantes, ${ }^{3}$ por lo que, cuando el primero se inicia en las artes de las letras, el segundo ya es un hombre maduro, con una gran experiencia vital a sus espaldas y no pocos fracasos literarios. Sus vidas discurrieron por caminos dispares; a la obvia diferencia de edad, debe sumarse una situación social y económica muy diferente. Aun así, coinciden en las mismas ciudades en dos momentos y es muy posible que entonces llegasen a conocerse. La primera vez pudo ser en el año 1604, cuando la Corte se encontraba en Valladolid, ciudad a la cual, desde el año 1600, fueron llegando escritores, unos ya con una reconocida obra, caso de Góngora, otros de cierta edad, intentando hallar la senda que les diese una vida acomodada y tranquila, caso de Cervantes, y otros en busca de notoriedad, como Quevedo.

Cervantes recalará en Valladolid después de viajar a Italia, pasar por el ejército, quedar manco de la mano izquierda por un arcabuzado recibido en la batalla de Lepanto, ser apresado por el turco y sufrir un largo cautiverio en Argel, conocer la prisión en la Península, y, tras escribir y

1 Una versión extensa de este trabajo se expuso en el II Curso-Simposio "Cervantes y el Quijote", dirigido por Antonio Rey Hazas y Juan de la Cruz Martín (Madrid, 31 de marzo de 2005), y se publicará en el volumen del mencionado curso con el título "Cervantes y Quevedo". Aquí se hace una revisión, a través de la obra de ambos autores, de aquellos aspectos que fluyen de uno a otro como resultado del aprovechamiento de la lectura de sus textos.

2 Véanse los trabajos de R. Lida, "Guerra y paz en un siglo de oro", en Estudios de Literatura Española ofrecidos a Marcos A. Morinigo, Madrid, Ínsula, 1971, págs. 57-76; F. Ayala, Cervantes y Quevedo, Barcelona, Ariel, 1984 ( $1^{\text {a }}$ ed. 1974); A. Sánchez, Cervantes y Quevedo: dos genios divergentes del humor hispánico, Madrid, Instituto Nacional de Enseñanza Media "Cervantes», 1981; J. Iffland, "Don Francisco, don Miguel y don Quijote: Un personaje en busca de su testamento», Edad de Oro, XIII (1994), págs. 65-83; M. Banura Badui de Zogbi, «El valiente Escarramán. De la jácara al entremés", en Cervantes, Góngora y Quevedo, Mendoza (República Argentina), Universidad Nacional de Cuyo, 1997, págs. 115-26, y en este volumen, F. Pedraza, "De Quevedo a Cervantes: la génesis de la jácara».

3 Sobre la vida de estos autores pueden leerse, entre otros, los trabajos de J. Canavaggio, Cervantes, en busca del perfil perdido, $2^{a}$ ed., Madrid, Espasa-Calpe, 1992; A. Rey y F. Sevilla, Cervantes vida y literatura, Madrid, Alianza Editorial, 1995, y A. Rey, Miguel de Cervantes. Literatura y vida, Madrid, Alianza Editorial, 2005 para Cervantes, y los de L. Astrana Marín, La vida turbulenta de Quevedo, Madrid, Gran Capitán, 1945, y P. Jauralde, Francisco de Quevedo (1580-1645), Madrid, Castalia, 1998 para Quevedo. 
publicar algunas de sus obras -varias poesías, El trato de Argel, La Numancia, La Galatea...- aún no ha saboreado las mieles del éxito.

Quevedo, en cambio, con poco más de 20 años, apenas había recorrido el trayecto que separa Palacio, en donde nació de la universidad, primero la de Alcalá y, posteriormente, la de Valladolid; no había todavía descubierto el amargor del destierro ni los rigores de la prisión leonesa que más tarde conocería. Su vida había transcurrido, como decíamos, entre las dependencias del Palacio Real destinadas al servicio, el colegio madrileño de los jesuitas y las Universidades de Alcalá de Henares y de Valladolid. Sus tempranos escritos debieron de tener gran aceptación entre sus contemporáneos, tal como prueba el elogioso soneto que Lope de Vega le dedica en La hermosura de Angélica (1602), cuyo primer verso dice: "Vos de Pisuerga nuevamente Amphriso», y la inclusión de casi una veintena de poemas en la antología preparada por Pedro de Espinosa, Flores de poetas ilustres $(1603,1605)$.

En este período vallisoletano, mientras Quevedo se carteaba con Justo Lipsio, polemizaba con Góngora, estrechaba su amistad con Lope, se granjeaba el favor de los poderosos y vivía holgadamente bajo la tutela de su pariente Agustín de Villanueva y, tal vez, con la protección de la Duquesa de Lerma, esposa del valido de Felipe III, ${ }^{4}$ Cervantes se acomodaba en los arrabales de la ciudad, rodeado de familiares, con más escasez que abundancia, y así, en esas precarias condiciones, ultimaba la primera parte del Quijote. ${ }^{5}$

Es posible que no llegaran a conocerse cuando Cervantes se instala en Valladolid, pues, si es cierto lo que el hiperbólico biógrafo de Quevedo, Astrana Marín, dice, por las fechas en las que Cervantes (1604) llega a la Corte, Quevedo se encuentra postrado en cama a causa de la misma enfermedad sufrida tiempo atrás: «la dolencia padecida en la primavera de 1602 vino a reproducirse, y a mediados de agosto de 1604, por los días en que entraba en la corte Miguel de Cervantes [...], cayó gravemente enfermo, de "romanizo" [...]; quizá de pulmonía..6

Mas es difícil creer que no tuviesen el uno noticias del otro, y, a pesar de no disponer de documentación que lo atestigue, lo cierto es que la pluma de Quevedo se hizo notar en la Corte vallisoletana, sus diatribas con Góngora, por ejemplo, tuvieron que andar de boca en boca y correr de manuscrito en manuscrito, por lo que estos inicios literarios de Quevedo no pudieron pasar desapercibidos ante los atentos ojos de Cervantes, de la misma manera que el personaje creado por Cervantes, nos referimos a don Quijote, ya era conocido por algunos antes de la publicación de la primera parte de su novela, entre los que figura Lope, amigo de Quevedo, tal como nos recuerda Antonio Rey: «En agosto de 1604, en cualquier caso, escribe Lope una carta en la que afirma que no hay ningún poeta "tan malo como Cervantes, ni tan necio que alabe a Don Quijote" ", 7 y, en 1605, cuando se imprime esa primera parte del Quijote, Quevedo se haría conocedor de ella con toda probabilidad.

Con el retorno de la Corte a Madrid, ambos autores vienen a instalarse en esta villa. Sus encuentros, a partir de 1606, son casi seguros, ya que pasearán las mismas calles y, lo que es más importante, acuden a las mismas devociones religiosas, "Como la Congregación de los Esclavos del Santísimo Sacramento del Olivar, a la que pertenecía [Cervantes] desde 1609, junto con Lope, Quevedo, Espinel, Salas Barbadillo y otros ${ }^{8}{ }^{8}$ frecuentan la tertulia literaria presidida por el padre Maiedo 9 y la academia del Conde de Saldaña. ${ }^{10}$

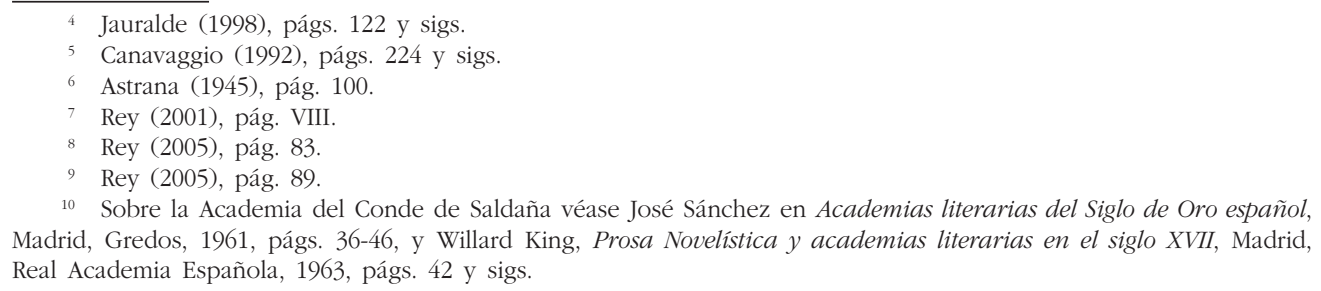

10 Sobre la Academia del Conde de Saldaña véase José Sánchez en Academias literarias del Siglo de Oro español, Madrid, Gredos, 1961, págs. 36-46, y Willard King, Prosa Novelística y academias literarias en el siglo XVII, Madrid, Real Academia Española, 1963, págs. 42 y sigs. 
La academia del Conde de Saldaña, según declara Duque de Estrada en su vida, ya se reunía en Valladolid, en el año 1603, ${ }^{11}$ y aquí destaca, de entre los asistentes a ella, la figura de Lope de Vega, sin hacer ninguna mención a Cervantes. ${ }^{12}$ Pero también se ha indicado el día 19 de noviembre de 1611 como día de su reunión primera en Madrid, así se lo comunica Lope de Vega en carta al Duque de Sessa. ${ }^{13}$ Y es aquí donde Lope, en otra de las cartas dirigidas al Duque de Sessa, escribe: "Las academias están furiosas: en la pasada se tiraron los bonetes dos licenciados; yo ley unos versos con vnos antojos de Zerbantes que pareçian guevos estrellados mal echos». ${ }^{14}$ Como dice José Sánchez, estas cartas en las que se hace referencia a la Academia de Saldaña y a Cervantes son conocidísimas por todos, pero es necesario volver a aludir a ellas, ya que se trata de una referencia concreta que nos permite poner en relación a los dos autores que nos ocupan.

Desgraciadamente, no conocemos ningún manuscrito que certeramente se asocie con esta academia. Nuestra Biblioteca Nacional conserva uno, ms. 3700, que se ha pensado que proceda de la Academia del Conde de Saldaña, puesto que con mano de comienzos del siglo XVII se copian poemas de muchos de los autores que la integraron (Lope, Góngora, Quevedo, los Argensola, el mismo Conde de Saldaña...), ${ }^{15}$ pero ninguno de los textos es encabezado por el nombre de Cervantes. Quizá, entre alguno de los anónimos se esconda el autor alcalaíno. Por tanto, como hemos dicho, tenemos que quedarnos con la referencia de Lope para atestiguar la presencia de Miguel de Cervantes en la misma academia que frecuentaba Francisco de Quevedo a su regreso de Valladolid.

La relación que los dos autores pudieron establecer a partir del año 1604 nos interesa en la medida que ésta se manifiesta en sus obras. Cervantes destacó como escritor de novelas, convirtiéndose ante los ojos del satírico madrileño en paradigma, conclusión a la que podemos llegar tras leer la dura crítica que realiza en la Perinola a las escritas por Pérez de Montalbán, de las que dice: "Las novelas [...] no son ni fábulas, ni comedias, ni consejas, ni no-velas, ni sí-velas, ni candiles [...] Y para agravarlas más, las hizo tan largas como pesadas, con poco temor y reverencia de las que imprimió el ingeniosísimo Miguel de Cervantes». ${ }^{16} \mathrm{E}$ insiste en ello Quevedo al final de la misma obra: "Deje vuesa merced de alabarse de muy honrado y muy modesto [...] y deje de encarecer sus sonetos; y deje las novelas para Cervantes». ${ }^{17}$

Con las dos citas anteriores queda patente, en un principio, el gusto y admiración que causaron en Quevedo las Novelas ejemplares del autor del Quijote y el aprovechamiento, quizá algo pobre, que hizo de ellas, puesto que aparentemente sólo han sido empleadas en la Perinola para situarlas como contrapunto respecto a las del autor del Para todos y así menospreciar las novelas escritas por Juan Pérez de Montalbán. ${ }^{18}$

${ }_{11}$ Diego Duque de Estrada nace en el año 1589, en el comienzo de la «Parte Segunda» de su vida dice que entra en la corte a la edad de catorce años, por tanto, se trata del año 1603 cuando llega a Valladolid. Véase D. Duque de Estrada, Comentarios del desengañado de sí mismo. Vida del mismo autor, ed. de Henry Ettinghausen, Madrid, Castalia, 1983, pág. 95.

12 Duque de Estrada, pág. 96.

13 Vega L. de Carpio, Epistolario, ed. A. G. de Amezúa, ed. facs., Madrid, Real Academia Española, 1989, vol. III, pág. 76 .

14 Vega Carpio, Epistolario, pág. 95.

15 J. Pérez de Guzmán, "La labor político-literaria del Conde-duque de Olivares", Revista de Archivos, Bibliotecas y Museos, XI (1904), pág. 86, y Sánchez (1961), pág. 317, nota 51, se encuentran entre los partidarios de adjudicar este manuscrito a la Academia del Conde de Saldaña; Clara Giménez, "Poesía de academias", Manuscrt.CAO, II (1989), ofrece un argumento más a favor de la pertenencia de este manuscrito a dicha academia, cuando apunta que en él se copia una poesía que Lope menciona en su epistolario al hablar de ella (pág. 49).

16 Quevedo hace aquí referencia a las Novelas ejemplares de Cervantes impresas en 1613. Quevedo, Prosa festiva completa, ed. de García-Valdés, Madrid, Cátedra, 1993, págs. 489-90.

17 Quevedo, Prosa festiva completa, pág. 507.

18 Pérez de Montalbán había llamado también ejemplares a las que escribió y recogió bajo el título de Sucesos $y$ prodigios de amor. 
Las citas a la obra de Cervantes que hallamos en los textos quevedianos no son muy abundantes. Por razones obvias de espacio, nos centraremos en el personaje de don Quijote y en cómo es utilizado por el satírico madrileño.

Tal vez podamos encontrar una reminiscencia de la novela cervantina en el Buscón, cuando el autor hace que Pablos de Segovia monte un rucio de la Mancha: "Yo iba caballero -nos dice- en el rucio de la Mancha, y bien deseoso de no topar con nadie, cuando de lejos vi venir un hidalgom. ${ }^{19}$

Éste es un pasaje muy discutido por los editores de esta obra de Quevedo, ya que muchos han querido ver en ella una alusión velada a la obra de Cervantes y otros la han considerado una simple burla o chiste quevediano. Lázaro Carreter, partidario de la segunda opción, señala que "Pablos alude a un rucio rodado, es decir, a un jumento gris o blanco con manchas oscuras. Rodado y manchado funcionan, en la lengua chistosa de aquel tiempo, como términos sinónimos; y manchado era, burlescamente, hasta para el propio Cervantes, el natural de la Mancha” y añade en nota que, a don Quijote, Cervantes le llamará "león manchado». Aunque también deja la puerta abierta a la otra posibilidad cuando dice a continuación: «No es, además, improbable que Quevedo conociera la obra cervantina antes de su publicación». ${ }^{20}$ Por su lado, Domingo Ynduráin, no duda de que se trata de un recuerdo al rucio de Sancho, recuerdo que considera reforzado por ir el rucio seguido de la aparición de un hidalgo. ${ }^{21}$ Este argumento lo creemos más sólido que el de Jauralde que, acudiendo a su "parecer», opina que la mención al rucio "es demasiado confusa como para aludir al Quijote, y no es el modo de referencia a obras o autores de la época que encontramos en el Buscón».22 Quizá no sea éste el modo de referencia habitual en El Buscón, pero sí que lo es en toda la literatura áurea y, por supuesto, de Quevedo en otros muchos de sus textos.

Francisco de Quevedo, sin duda alguna, leyó a Cervantes, pero el aprovechamiento que hizo de esa lectura se transfiere a su obra en contadas ocasiones. Además de las ya mencionadas alusiones recogidas en la Perinola y la recién citada del Buscón, podemos apuntar otras tres más al personaje de don Quijote, que es lo que ahora nos ocupa.

Una, la realiza en La Fortuna con seso y la hora de todos, en el comienzo de la obra, cuando Júpiter, furioso, reúne en consejo a los dioses del Olimpo, dice: «Marte, don Quijote de las deidades, entró con sus armas y capacete y la insignia de viñadero enristrada, echando chuzos».23

Como podemos ver, Quevedo reduce al dios de la guerra a un "Quijote de las deidades", es decir, Marte es transformado en un loco caballero andante, con una serie de atributos que lo convierten en un habitante ridículo del Olimpo, ya que, en vez de lanza en ristre y escudo, tal como se le representa, lleva un capacete -armadura que cubre la cabeza, aunque también capacete puede ser abreviatura de capazo, por tanto, capacho de esparto donde se ponen, por ejemplo, las uvas- y enristrada la insignia que le identifica como viñadero o cuidador de las viñas. Así que Quevedo sólo alude al personaje cervantino para degradar a Marte y anunciar al lector que va encontrarse a un dios de la guerra ridículo, apuntando, con los objetos que porta Marte, hacia el dios Baco, que hará su entrada seguidamente.

Otra referencia a don Quijote la encontraremos en la Sátira contra Francisco Morovelli de la Puebla. Esta composición comparte con el Poema heroico de las necedades y locuras de Orlando, también de Quevedo, cinco octavas de las ocho que la forman, ${ }^{24}$ suponiendo las de la

19 Quevedo, La vida del Buscón, ed. Cabo Aseguinolaza, Barcelona, Crítica, 1993, pág. 141.

20 F. Lázaro Carreter, "Estudio preliminar", en Francisco de Quevedo, La vida del Buscón llamado don Pablos, $2^{\text {a }}$ ed., Salamanca, Universidad, 1980, pág. LIV y nota 68.

${ }_{21}$ Quevedo, La vida del Buscón, ed. Ynduráin, $5^{a}$ ed., Madrid, Cátedra, 1983, pág. 187, nota 222.

22 Quevedo, El Buscón, ed. Jauralde, Madrid, Castalia, 1990, págs. 170-71, nota 151.

23 Quevedo, La Fortuna con seso y la hora de todos. Fantasía Moral, ed. de Lía Schwartz, en Obras completas en prosa, Madrid, Castalia, 2003, vol. I, t. II, págs. 577-79.

24 En la edición de Blecua con el número 875, la Sátira contra Francisco Morovelli es editada en nota a pie de página (Quevedo, Obra poética, Madrid, Castalia, 1971, vol. III, págs. 411-52 para el Poema heroico, y págs. 412-14 para la Sátira). 
Sátira una versión ligeramente distinta de las del Poema heroico. Crosby, sostiene que la redacción del Poema es anterior a la de la Sátira, ${ }^{25}$ mientras que Blecua defiende lo contrario, por lo que afirma que las octavas contra Morovelli son una versión primitiva de las Necedades y locuras de Orlando. ${ }^{26}$ Fuese como fuese, este asunto ahora nos aleja del nuestro. Lo que nos interesa es que la mención a don Quijote, como se ha dicho, sólo está presente en la Sátira. Después de descalificar a Francisco Morovelli durísimamente -le llama postema de la vida humana, afrenta de la infamia, peste de la verdad, alma descomulgada, judío-, cierra la retahíla de insultos comparándolo con don Quijote por sus desatinos o locuras, despropósitos o disparates, todos cuatro sinónimos. Quevedo se ha quedado, como hizo en La Fortuna con seso, con la imagen del loco y ridículo caballero andante que de continuo convierte sus acciones en despropósitos.

Finalizamos con el romance que dedica al personaje cervantino, cuyo título es Testamento de don Quijote. ${ }^{27}$ Crosby ha fechado esta composición en el año 1615 o posterior por las referencias a la segunda parte de la obra de Cervantes, ${ }^{28}$ aunque son más frecuentes las que hace Quevedo a la primera. ${ }^{29}$

Los dos testamentos que tenemos de don Quijote, uno el redactado por el personaje creado por Cervantes y otro el dictado por el Quijote apócrifo de Quevedo, son bien distintos. El primero es el de un hombre que ha recuperado el juicio y, por tanto, es la cordura la que guía sus palabras al testar; es ahora éste un personaje que mueve a la compasión, que provoca llanto y no risa. Sin embargo, el segundo, el compuesto por Francisco de Quevedo, es el testamento de un loco que con su última voluntad provoca la hilaridad en el lector.

En el mismo momento de pronunciar su última voluntad, Quevedo sitúa a don Quijote tendido en el suelo, como una tortuga, y en esa posición comienza el dictado de un disparatado testamento, con una voz agotada (roída), chillando y sin dientes, en cuyo inicio, el personaje ya se declara un hombre loco y así se lo hace saber al escribano para que lo haga constar en el documento (vv. 17-20).

Hará beneficiarios de un absurdo legado a su escudero, a su caballo, al moro encantado, a los mozos de mulas, ${ }^{30}$ y a Dulcinea (vv. 37-60). Su espada, también presente en estas disposiciones testamentarias, no será esgrimida por otra mano, como así ocurría con las que pertenecieron a los caballeros valerosos, aunque Quevedo, que no puede evitar introducir la burla, toma como punto de partida esta costumbre para continuar la parodia, y lejos de ser éste un objeto reservado para ser venerado hará que quede arrumbado de un simple gancho para que el orín lo cubra, y la lanza, que acompañó a don Quijote en tantos episodios, no corre mejor suerte, ya que una labor doméstica será su nuevo cometido (vv. 61-68). Y así continua con los demás elementos que configuran la indumentaria propia de un caballero: peto, gola, espaldar, manopla (vv. 69 y sigs.). Los albaceas elegidos por don Quijote de todos estos desatinos serán tres caballeros (Belianís de Grecia, el caballero de Febo y Esplandián) mencionados por Cervantes en su novela (vv. 81-85). De tal manera se dispone la última voluntad del caballero andante que todo el testamento, como dice cuerdamente Sancho, está repleto de «sandeces» (vv. 89-92).

25 J. O. Crosby, En torno a la poesía de Quevedo, Madrid, Castalia, 1967, págs. 45-46.

26 Quevedo, Obra poética, vol. III, pág. 411.

27 En la edición de Blecua con el número 733 (Quevedo, Obra poética, Madrid, Castalia, 1969, vol. II, págs. 459-62).

28 Crosby (1967), pág. 120.

29 Sobre esto puede leerse el trabajo de Alberto Sánchez, Cervantes y Quevedo: dos genios divergentes del humor bispánico, Madrid, Publicaciones del Instituto Nacional de Enseñanza Media "Cervantes», 1981.

30 Ambas alusiones hacen referencia, respectivamente, a los capítulos XVII y IV de la primera parte. En ellos don Quijote será maltratado: en el primero, un cuadrillero le golpea con un candil en la cabeza y, por quedarse a oscuras, Sancho considera que el responsable del golpe es el "moro encantado"; en el segundo capítulo citado, el caballero recibe una tremenda paliza de un mozo de mulas que, después de haberle roto la lanza, le golpea con los trozos de ésta de manera incansable. 
Quevedo, una vez más, ridiculiza al personaje de don Quijote y para ello se vale de su escudero, de su dama, de su caballo y de sus armas, todos ellos elementos fundamentales que fijan en la memoria colectiva la imagen del caballero andante. A ellos se han sumado algunas referencias a episodios en los que siempre el personaje cervantino ha sido duramente golpeado. La burla está servida y con ella no sólo parodia el testamento original, el de la novela, ya que en éste, el hidalgo actúa con cordura y así nombra como albaceas al cura y al bachiller Sansón Carrasco, deja la hacienda a su descendiente más directa, la sobrina, y al fiel Sancho le cede los dineros que sobraren una vez saldadas las deudas, sino que también caricaturiza al personaje creado por Cervantes. Quevedo ha logrado su objetivo primordial, ofrecer la ridiculización descarnada de un personaje apaleado, vencido y yacente, que en ningún momento conmueve al lector hacia la lástima, sino hacia la risa.

Como hemos visto, en las tres obras de Quevedo, La Fortuna con seso, la Sátira contra Francisco Morovelli y el Testamento de don Quijote, se ha empleado a don Quijote para caricaturizar a otro personaje, para descalificar a un enemigo personal y para realizar una parodia del personaje de la novela cervantina. La imagen que ha ofrecido de don Quijote en los tres textos es la del ridículo y loco caballero, la misma que captaron sus contemporáneos y la misma que quedó fijada en el diccionario de Autoridades: "Quixote: se llama al hombre ridículamente serio, o empeñado en lo que no le toca»; y "Quixotería: el modo o porte ridículo de proceder». 